\title{
Magnesium hydroxide reinforced kenaf fibers/epoxy hybrid composites: mechanical and thermomechanical properties
}

\begin{abstract}
The present article deals with the fabrication of magnesium hydroxide ( $\mathrm{MH})$ filler reinforced kenaf/epoxy hybrid composites with different loading (10\%, 15\%, 20\% and 25\% by wt). Tensile, impact, flexural, morphological, thermal stability and dynamic mechanical properties of the developed $\mathrm{MH} /$ kenaf/epoxy hybrid composites were evaluated and compared. The analysis of the results revealed that the incorporation of the stiff $\mathrm{MH}$ particles into the kenaf/epoxy composites enhanced their tensile, flexural and impact properties, as well as their residual content. Enhancement in both storage $\left(E^{\prime}\right)$ and loss $\left(E^{\prime \prime}\right)$ moduli, as well as a considerable decrease in damping factor $(\operatorname{Tan} \delta$ ), was observed in the hybrid composites, compared to the kenaf/epoxy composites. Moreover, a remarkable improvement in properties was noticed for the $20 \% \mathrm{MH}$ hybrid composites, which was ascribed to better dispersion and interfacial interaction between the kenaf fibers and the epoxy within composites, enabling more efficient interfacial stress transfer. Overall, the $20 \% \mathrm{MH} /$ kenaf/epoxy hybrid composites presented better mechanical strength, thermal stability and dynamic properties compared to the rest of the hybrid composites developed in this study.
\end{abstract}

Keyword: Kenaf fibers; Epoxy; Magnesium hydroxide; Thermal stability; Dynamic mechanical properties; Damping factor 